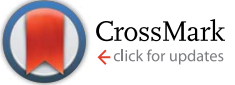

Cite this: RSC Adv., 2016, 6, 260

Received 3rd November 2015 Accepted 11th December 2015

DOI: 10.1039/c5ra23134e

www.rsc.org/advances

\section{Synthesis, structure and characterization of a layered coordination polymer based on $\mathrm{Zn(II)}$ and 6-(methylmercapto)purine $\uparrow$}

\author{
Adelaida Perea-Cachero, ${ }^{a}$ Beatriz Seoane, ${ }^{\mathrm{ab}}$ Beatriz Diosdado, ${ }^{\mathrm{C}}$ Carlos Téllez ${ }^{\star a}$ \\ and Joaquín Coronas ${ }^{a}$
}

\begin{abstract}
A layered coordination polymer (LCP) named UZAR-S12 was synthesized. Its structure and formula $Z_{2 n_{2}}\left(\mu_{2^{-}}\right.$ $\left.\mathrm{mMP}_{3}\left(\mathrm{NO}_{3}\right)(\mathrm{DMF})\left(\mathrm{H}_{2} \mathrm{O}\right)\right]_{n} \cdot \mathrm{nDMF}$ (mMP, 6-(methylmercapto)purinate; DMF, N,N-dimethylformamide) were determined by single crystal X-ray diffraction. UZAR-S12 is characterized by two kinds of Zn centres. Zn1 is bonded to three MMP ligands at the basal plane, and one water molecule and one DMF molecule at the axial positions, giving rise to a slightly distorted trigonal bipyramidal geometry. $\mathrm{Zn} 2$ is coordinated to three $\mathrm{mMP}$ linkers and one $\mathrm{NO}_{3}{ }^{-}$resulting in a tetrahedral environment. The layers are arranged yielding a threedimensional network with guest DMF trapped between them. Lattice and coordination DMF can be replaced reversibly by other solvents producing a contraction (methanol) or an expansion $(N, N-$ diethylformamide) of the framework. A solvent exchange method was used from the vapour phase which preserved the sample crystallinity.
\end{abstract}

\section{Introduction}

Coordination polymers (CPs) are infinite arrays formed by metal ions or clusters connected through organic molecules via coordination bonds giving rise to one-, two- or threedimensional structures. ${ }^{1,2}$ The physical and chemical properties of CPs allow their use in magnetic, ${ }^{3}$ luminescence ${ }^{4,5}$ and electrical conductive ${ }^{6}$ applications. CPs with porous structures, called porous coordination polymers (PCPs) or metal-organic frameworks (MOFs), have attracted increasing attention due to their unique properties such as large surface areas, elevated pore volumes, ${ }^{7,8}$ and flexibility. ${ }^{9}$

Crystalline layered materials have been awakening special interest due to their exceptional physicochemical features arising from their two-dimensional structures ${ }^{\mathbf{1 0}}$ (mechanical strength, size- and shape-dependent electronic and optical properties, and high surface areas). ${ }^{\mathbf{1 1}}$ Among them, layered coordination polymers (LCPs) are intensively studied because their chemical surfaces and structures can be designed by

${ }^{a}$ Chemical and Environmental Engineering Department and Instituto de Nanociencia de Aragón (INA), Universidad de Zaragoza, 50018 Zaragoza, Spain. E-mail: ctellez@ unizar.es

${ }^{b}$ Catalysis Engineering, ChemE, Delft University of Technology, 2628 BL Delft, The Netherlands

${ }^{c} X$-ray Diffraction and Fluorescence Analysis Service, Universidad de Zaragoza, 50009 Zaragoza, Spain

$\dagger$ Electronic supplementary information (ESI) available: Additional figures, SEM images, FTIR spectra, gas sorption isotherms and PXRD patterns. CCDC 1411214 and 1411215. For ESI and crystallographic data in CIF or other electronic format see DOI: 10.1039/c5ra23134e selecting the ideal organic motif. ${ }^{\mathbf{1 2}}$ Therefore, the interlayer interactions and the flexibility of the coordination bonds are also tunable by choosing the appropriate metal and ligand components. $^{13}$ Considering this flexibility and that twodimensional networks can adapt guest molecules between layers, ${ }^{14}$ selective gas adsorption is expected as an important application for this kind of compounds. ${ }^{13,15}$ Others uses of LCPs are catalysis, ${ }^{\mathbf{1 6}, 17}$ molecular recognition, ${ }^{\mathbf{1 8}}$ thin films for technological applications, ${ }^{19,20}$ and electrode materials. ${ }^{21,22}$

$\mathrm{Zn}$ (II) is a metal cation of great interest and importance in biological systems ${ }^{23,24}$ and bioinorganic chemistry. ${ }^{25}$ It can bind to oxygen, nitrogen and sulphur atoms from donor organic linkers to build up CPs with different coordination numbers and geometries (e.g. square pyramidal, trigonal bipyramidal or octahedral). ${ }^{24,25}$ Nucleobases are nitrogenous biological compounds which are part of DNA and RNA. As nucleobases contain multiple donor sites, they can act as ligands in coordination networks useful in medicine, industry, agriculture and coordination chemistry. ${ }^{26}$ There are several examples of LCPs based on $\mathrm{Zn}^{27-37}$ or nucleobases, ${ }^{38-44}$ but just a few based on the $\mathrm{Zn}$ and nucleobase combination. ${ }^{\mathbf{4 5 , 4 6}}$

Here, we report the synthesis and characterization of a new LCP named UZAR-S12 (henceforth referred to as 1). It is constructed from $\mathrm{Zn}$ as the metal cation and 6-(methylmercapto) purine (hereafter $\mathrm{mMP}-\mathrm{H}$ ) as the ligand, a nucleobase with the thiomethyl $\left(-\mathrm{SCH}_{3}\right)$ function (see Fig. 1a). To the best of our knowledge, 1 is the first $\mathrm{CP}$ which contains $\mathrm{MMP}$ in its skeleton. Initially 6-mercaptopurine, another nucleobase which possesses the thiol/thione group as a substituent (Fig. 1b), was selected as the organic building unit instead of mMP-H. 
(a)

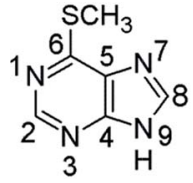

(b)

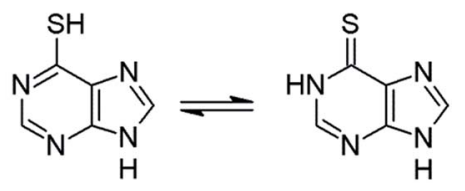

Fig. 1 Schematic representation of (a) 6-(methylmercapto)purine (mMP-H) and (b) thiol (left) and thione (right) forms of 6mercaptopurine.

Nonetheless, both nitrogen at 7-position and sulphur atoms coordinated to the metal ion blocking the function from the ligand, as observed in other works. ${ }^{47-49}$ Thus mMP-H was chosen to prevent the coordination of sulphur atoms due to the presence of the methyl group. Framework 1 is capable of fitting methanol (MeOH) and $N, N$-diethylformamide (DEF) molecules when they are inserted into its structure, producing a different phase with each solvent. If the solvent of the synthesis $(\mathrm{N}, \mathrm{N}-$ dimethylformamide, DMF) is introduced, the initial structure is mostly and totally recovered for DEF and $\mathrm{MeOH}$ exchanged forms, respectively. The flexibility of material 1 would offer the possibility of using it as a sensor or gas adsorbent, among other applications.

\section{Experimental section}

\section{General methods and materials}

Zinc nitrate hexahydrate $\left(\mathrm{Zn}\left(\mathrm{NO}_{3}\right)_{2} \cdot 6 \mathrm{H}_{2} \mathrm{O}, 98 \%\right.$, Sigma-Aldrich), 6-(methylmercapto)purine $\left(\mathrm{C}_{6} \mathrm{H}_{6} \mathrm{~N}_{4} \mathrm{~S}, 97 \%\right.$, Alfa Aesar), methanol $\left(\mathrm{CH}_{3} \mathrm{OH}, 99.9 \%\right.$, Scharlau $), \quad N, N$-dimethylformamide $\left(\mathrm{HCON}\left(\mathrm{CH}_{3}\right)_{2}, \quad 99.95 \%, \quad\right.$ Scharlau), N,N-diethylformamide $\left(\mathrm{HCON}\left(\mathrm{CH}_{2} \mathrm{CH}_{3}\right)_{2}, 99 \%\right.$, Alfa Aesar), and anhydrous chloroform $\left(\mathrm{CHCl}_{3}, 99 \%\right.$, Sigma-Aldrich) were used as received without further purification.

\section{Terminology}

In this work different structures have been developed: $\mathbf{1}, \mathbf{1}^{\prime}, \mathbf{2}$ and 3 (Fig. 2). 2 and $\mathbf{3}$ were obtained from $\mathbf{1}$ through an exchange

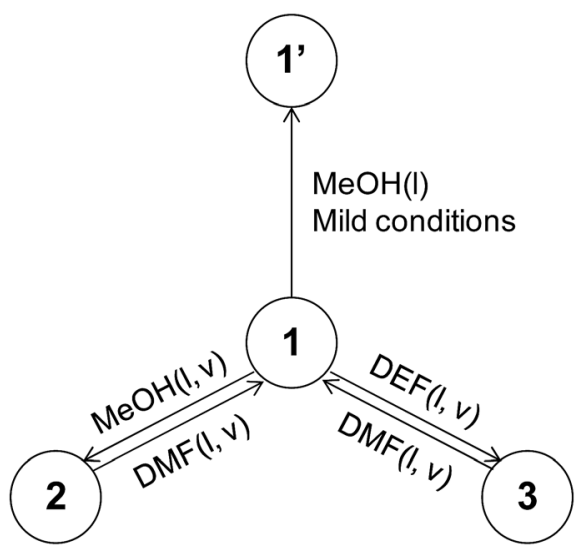

Fig. 2 Simplified schematic representation of DMF exchange and framework recovery processes described in this work. Mild conditions refer to the immersion in liquid $\mathrm{MeOH}$ without stirring.

of lattice (crystallization) and coordination DMF for $\mathrm{MeOH}$ and DEF, respectively (see below). These exchange processes were carried out with the solvent in liquid and/or vapour phase. A nomenclature method is used in order to distinguish both pathways: $x \_s o l v e n t l$ or $x \_s o l v e n t v$. $x$ denotes the structure obtained after exchange, solvent indicates the solvent utilized, and 1 or v denotes the use of liquid or vapour solvent, respectively. $\mathbf{1}^{\prime}$ was obtained from 1 upon a mild exchange with liquid $\mathrm{MeOH}$. In addition, it was possible to recover the framework of $\mathbf{1}$ from 2 and 3 replacing $\mathrm{MeOH}$ and DEF, respectively, by DMF. In this case, the terminology is 1_MeOHI_DMFp or 1_DEFv_DMFp. In 1_MeOHl_DMFp the structure of $\mathbf{1}$ was reacquired from 2_MeOHl. In 1_DEFv_DMFp it was achieved from 3_DEFv. p could be 1 or $\mathrm{v}$ indicating the use of liquid or vapour DMF, respectively. It is worth mentioning that in these exchange processes the dissolution and recrystallization of the solid do not take place, but rather a transformation of the material.

\section{Synthesis of $\left[\mathrm{Zn}_{2}\left(\mu_{2}-\mathrm{mMP}\right)_{3}\left(\mathrm{NO}_{3}\right)(\mathrm{DMF})\left(\mathrm{H}_{2} \mathrm{O}\right)\right]_{n} \cdot \mathrm{nDMF}(1)$}

1 was prepared by synthesis of $0.2230 \mathrm{~g}$ of zinc nitrate hexahydrate and $0.6232 \mathrm{~g}$ of mMP-H in $5 \mathrm{~mL}$ of DMF. The mixture was stirred for $30 \mathrm{~min}$. The suspension was poured into a stainless steel Teflon-lined autoclave which was heated in an air oven at $65{ }^{\circ} \mathrm{C}$ for $4 \mathrm{~d}$. After cooling to room temperature, the product was separated by centrifugation, washed 3 times with fresh DMF and dried in air at ambient temperature (yield $c a .60 \%$ based on $\mathrm{Zn})$. Elemental microanalysis calculated for $\mathbf{1}\left(\mathrm{C}_{24^{-}}\right.$ $\mathrm{H}_{31} \mathrm{~N}_{15} \mathrm{O}_{6} \mathrm{~S}_{3} \mathrm{Zn}_{2}$ ): C, 33.81; H, 3.67; N, 24.64; S, 11.28. Found: C, 33.46; H, 3.46; N, 24.84; S, 11.12.

\section{Purification of 1}

After washing the product of the synthesis with fresh DMF, the wet solid was placed inside a test tube with approximately $10 \mathrm{~mL}$ of anhydrous chloroform. The tube was slightly shaken dispersing the material in the solvent. In a few seconds, big crystals decanted while small particles remained dispersed. The fine particles were readily removed by means of a long pipette until there was no solvent. This process was repeated 5 times. Finally, bare crystals of $\mathbf{1}$ were dried at ambient temperature in air.

\section{Desolvation of 1}

After studying distinct conditions for exchanging coordination DMF for MeOH (see below), desolvated $\mathbf{1}$, termed $\mathbf{1}^{\prime}$, was obtained. $\mathbf{1}^{\prime}$ was produced after a mild exchange in liquid $\mathrm{MeOH}$ for $3 \mathrm{~d}$ at room temperature without stirring. $\mathrm{MeOH}$ was refreshed once a day.

\section{Exchange of molecules}

DMF replaced by $\mathrm{MeOH}$. $\mathrm{MeOH}$ molecules were inserted in the skeleton of $\mathbf{1}$ to replace DMF by means of two procedures: with liquid or vapour $\mathrm{MeOH}$. In the liquid phase method, product 1 was soaked in $\mathrm{MeOH}$ with stirring at room temperature. This solvent was refreshed once per day. After $3 \mathrm{~d}$, the soaking solution was removed and the product was dried in air at room temperature. The material formed was named 
2_MeOHl. The vapour phase process was carried out at room temperature for up to $45 \mathrm{~d}$. Solid 1 was placed in a $50 \mathrm{~mL}$ glass beaker. Then this beaker was put inside a $500 \mathrm{~mL}$ glass beaker with roughly $6 \mathrm{~mL}$ of solvent. The latter beaker was covered with Parafilm, though a tiny hole was made with a needle to avoid vapour condensation and ensure saturation. $\mathrm{MeOH}$ was replaced every 7 or $8 \mathrm{~d}$. The product obtained was called 2_MeOHv. A schematic representation (Fig. S1a $\dagger$ ) and a photograph (Fig. S1b $\dagger$ ) of this procedure are exhibited in the ESI. $\dagger$

DMF replaced by DEF. Liquid DEF incorporation was identical to the $\mathrm{MeOH}$ case. The solid produced was termed 3_DEFl. For the vapour phase process, the temperature and time were modified. DMF replacement was carried out at $80{ }^{\circ} \mathrm{C}$ for 7 d forming 3_DEFv.

\section{Recovery of the framework}

MeOH replaced by DMF. The same two methods used in $\mathrm{MeOH}$ and DEF insertion were employed but replacing the corresponding solvent by DMF. The starting material for the recovery of framework 1 was 2_MeOHl. The samples produced were called 1_MeOHl_DMFl or 1_MeOHl_DMFv. Both the material dipped in liquid solvent and the sample in contact with vapour DMF were exchanged for up to $7 \mathrm{~d}$ at room temperature.

DEF replaced by DMF. 3_DEFv was employed as the starting material for recovering the structure of $\mathbf{1}$ after DEF insertion. The product obtained with liquid DMF was termed 1_DEFv_DMFl. The vapour phase exchange was produced at ambient temperature for up to $35 \mathrm{~d}$ forming the compound 1_DEFv_DMFv.

\section{Characterization methods}

Powder X-ray diffraction (PXRD) patterns were recorded at room temperature by means of a D-Max Rigaku diffractometer with a copper anode. A graphite monochromator was used to select CuK $\alpha$ radiation with $\lambda=1.5418 \AA$. Data were collected in a $2 \theta$ range of $2.5-40^{\circ}$ with a scanning rate of $0.03^{\circ} \mathrm{s}^{-1}$. Single crystal Xray diffraction data were gathered at room temperature in an Xcalibur S3 diffractometer with a graphite monochromator utilizing MoK $\alpha$ radiation $(\lambda=0.71073 \AA$ ). The diffraction frames were integrated and corrected for absorption using the program CrysAlisPro. ${ }^{50,51}$ The structures were solved by direct methods (SIR-92). ${ }^{52}$ All refinements were carried out by full-matrix leastsquares using ShelXL-2014/6. ${ }^{53}$ Computer molecular graphics were made with Diamond ${ }^{54}$ and Mercury. ${ }^{55}$ All non-hydrogen atoms were found by direct methods and refined with anisotropic displacement parameters. Hydrogen atoms were constrained to idealized geometries and refined as riders with isotropic displacement parameters assigned as 1.2 times the $U_{\text {eq }}$ value of the corresponding bonding partner (1.5 times for methyl hydrogen atoms). In structure 1 , hydrogen atoms of the $\mathrm{H}_{2} \mathrm{O}$ fragment were successfully located in difference maps (see Fig. S2 $\dagger$ ), included in the structure model, refined with restraints and assigned $U_{\text {iso }}=1.2 U_{\text {eq }}$. In structure $1^{\prime}$, these atoms could not be located and were omitted from the model. The crystal data and refinement results of both compounds are summarized in Table 1. ORTEP views of $\mathbf{1}$ and $\mathbf{1}^{\prime}$ are depicted in Fig. S3 and S4, $\dagger$ respectively. Scanning electron microscopy (SEM) images were taken using a FEI Inspect F50 microscope in the $2.00-5.00 \mathrm{kV}$ range. Samples were coated with platinum under vacuum conditions. Thermogravimetric analyses (TGA) of bulk powder were performed using a Mettler Toledo TGA/DSC $1 \mathrm{SF} / 755$ instrument. Samples were heated in a temperature range of $25-900{ }^{\circ} \mathrm{C}$ under air and/or nitrogen atmosphere with a heating rate of $5{ }^{\circ} \mathrm{C} \mathrm{min}^{-1}$. Fourier transform infrared (FTIR) spectra of bulk samples were measured from $\mathrm{KBr}$ pellets at room temperature employing a Shimadzu IRAffinity-1 spectrophotometer. Spectra were recorded in the $4000-400 \mathrm{~cm}^{-1}$ wavenumber range at a resolution of 4 $\mathrm{cm}^{-1}$ averaging 20 scans. $\mathrm{CO}_{2}$ adsorption was carried out at $273 \mathrm{~K}$ on a Micromeritics ASAP 2020 V1.04 H sorption analyser. Brunauer-Emmett-Teller (BET) specific surface area and $\mathrm{N}_{2}$ sorption were determined using a TriStar 3000 porosity analyser. 2_MeOHv products were used in both $\mathrm{CO}_{2}$ and $\mathrm{N}_{2}$ sorption. Previously, samples were outgassed at $100{ }^{\circ} \mathrm{C}$ for $8 \mathrm{~h}$ with a heating rate of 1 ${ }^{\circ} \mathrm{C} \min ^{-1}$. $\mathrm{CO}_{2}$ adsorption was repeated 4 times on the same sample calculating the final values of the adsorbed amount as an average of the measurements to cut down the random fluctuation. Elemental microanalysis of $\mathbf{1}$ was carried out using a Perkin Elmer 2400 Series II CHNS/O Elemental Analyser. Samples were combusted in a pure oxygen environment. The resultant combustion gases were measured in an automated fashion to determine weight percentages of $\mathrm{C}, \mathrm{H}, \mathrm{N}$ and $\mathrm{S}$.

\section{Results and discussion}

\section{Morphology and structure of 1}

The new material synthesized here is crystalline (as will be shown below). Two kinds of crystals are distinguished: type I and type II (Fig. 3a). Type I crystals are regular hexagonal prisms

Table 1 Crystal data and structure refinement details for 1 and $1^{\prime}$

\begin{tabular}{lll}
\hline Compound & $\mathbf{1}$ & $\mathbf{1}^{\prime}$ \\
\hline Empirical formula & $\mathrm{C}_{24} \mathrm{H}_{31} \mathrm{~N}_{15} \mathrm{O}_{6} \mathrm{~S}_{3} \mathrm{Zn}_{2}$ & $\mathrm{C}_{21} \mathrm{H}_{24} \mathrm{~N}_{14} \mathrm{O}_{5} \mathrm{~S}_{3} \mathrm{Zn}_{2}$ \\
Formula weight & 852.56 & 779.46 \\
Temperature $(\mathrm{K})$ & $296(1)$ & $296(1)$ \\
Crystal system & Monoclinic & Monoclinic \\
Space group & $P n$ & $P n$ \\
$a(\AA)$ & $11.6765(4)$ & $11.6757(8)$ \\
$b(\AA)$ & $10.3852(2)$ & $10.3908(4)$ \\
$c(\AA)$ & $15.0913(4)$ & $15.1045(7)$ \\
$\beta($ deg$)$ & $107.074(3)$ & $107.129(6)$ \\
$V\left(\AA^{3}\right)$ & $1749.36(9)$ & $1751.19(6)$ \\
$Z$ & 2 & 2 \\
$\rho_{\mathrm{c}}\left(\mathrm{g} \mathrm{cm}^{-3}\right)$ & 1.619 & 1.478 \\
$\left.\mu(\mathrm{mm})^{-1}\right)$ & 1.612 & 1.600 \\
Crystal size (mm $\left.{ }^{3}\right)$ & $0.160 \times 0.040 \times 0.030$ & $0.200 \times 0.040 \times 0.020$ \\
Reflections & $24135 / 6163$ & $18164 / 6141$ \\
collected/unique & & \\
$R_{\text {int }}$ & 0.0632 & 0.0996 \\
GooF & 1.042 & 1.007 \\
$R_{1}, \mathrm{w} R_{2}[I>2 \sigma(I)]$ & $0.0519,0.0956$ & $0.0704,0.1284$ \\
$R_{1}, \mathrm{w} R_{2}($ all data) & $0.0727,0.1035$ & $0.1311,0.1546$ \\
$\mathrm{CCDC}$ deposition & 1411214 & 1411215 \\
number & & \\
$a$ & &
\end{tabular}


whereas type II crystals have an irregular polyhedron shape. It is possible to observe small particles on them in (Fig. 3b). In order to obtain pristine crystals of $\mathbf{1}$ and solve its structure, a purification process was carried out, as explained in the Experimental section. A great amount of small particles disappeared and large particles are mainly seen (Fig. 3c).

The chemical formula of $\mathbf{1}$ obtained by single X-ray diffraction is $\left[\mathrm{Zn}_{2}\left(\mu_{2}-\mathrm{mMP}\right)_{3}\left(\mathrm{NO}_{3}\right)(\mathrm{DMF})\left(\mathrm{H}_{2} \mathrm{O}\right)\right]_{n} \cdot \mathrm{nDMF} .1$ crystallizes in a monoclinic system with the $P n$ space group. This space group is acentric and possesses an absolute structure parameter $^{56}$ refined to a value of $0.433(10)$ and Friedif $629 .{ }^{57}$ The structure is polar, as can be seen by visual inspection. 1 has a two-dimensional polymeric structure with two kinds of $\mathrm{Zn}$ atoms (Zn1 and Zn2) bridged by mMP ligands through their $\mathrm{N}$ atoms at positions 7 and 9 (Fig. 4a). The $\mathrm{Zn} 1$ centre is coordinated to three mMP ligands by N1, N5 and N10 (at positions 9, 7 and 9 , respectively, with the N10 atom belonging to a ligand generated by $0.5+x, 1-y, 0.5+z$ symmetry). The Zn1 and these $\mathrm{N}$ atoms are nearly coplanar. The axial positions of $\mathrm{Zn} 1$ are occupied by a DMF molecule and an $\mathrm{H}_{2} \mathrm{O}$ molecule (O1-Zn1$\left.\mathrm{O} 2,173.7(3)^{\circ}\right)$. Its pentacoordinated coordination sphere produces a slightly distorted trigonal bipyramidal geometry $(\tau=$ 0.77) based on the Addison parameter. ${ }^{58}$ The Addison parameter value is 1 for a perfect trigonal bipyramid and 0 for a perfect square pyramid. ${ }^{\mathbf{2 4 5 8}}$ The linker which contains the N1 is bridged to the $\mathrm{Zn} 2$ through the $\mathrm{N} 2$ atom (at 7-position). The ligand comprising the N5 atom is coordinated by the N6 (at position 9) to a Zn2 atom created by $0.5+x,-y, 0.5+z$ symmetry. The third ligand is bonded to the $\mathrm{Zn} 2$ centre by its $\mathrm{N} 9$ atom (at position 7 ). The Zn2 completes a distorted tetrahedral coordination environment with $\mathrm{a} \mathrm{NO}_{3}{ }^{-}$ion in monodentate fashion.

In the asymmetric part, two of the planes including mMP ligands are perpendicular to the third one (containing a N1 atom) with dihedral angles of 83.01, 79.85 and $3.95^{\circ}$ (Fig. S5†). Within a layer, the plane defined by the Zn1 atoms is separated by 1.166 $\AA$ from the plane determined by the $\mathrm{Zn} 2$ atoms. The distance between layers (10.434 $⿱$ ) has been assigned as the distance between planes containing the same type of $\mathrm{Zn}$ atoms (Fig. S6 $\dagger$ ). Lattice DMF molecules are placed between layers (one molecule of DMF per asymmetric unit) and layers are arranged forming a three-dimensional construction (Fig. 4b). Hydrogen bonds among the oxygen atom from lattice DMF molecules (O6) and one hydrogen atom from water ligand molecules are present.

Experimental PXRD patterns of the bulk sample were compared to simulated patterns from single crystal X-ray diffraction data (Fig. 5). A great similarity between both

(a)
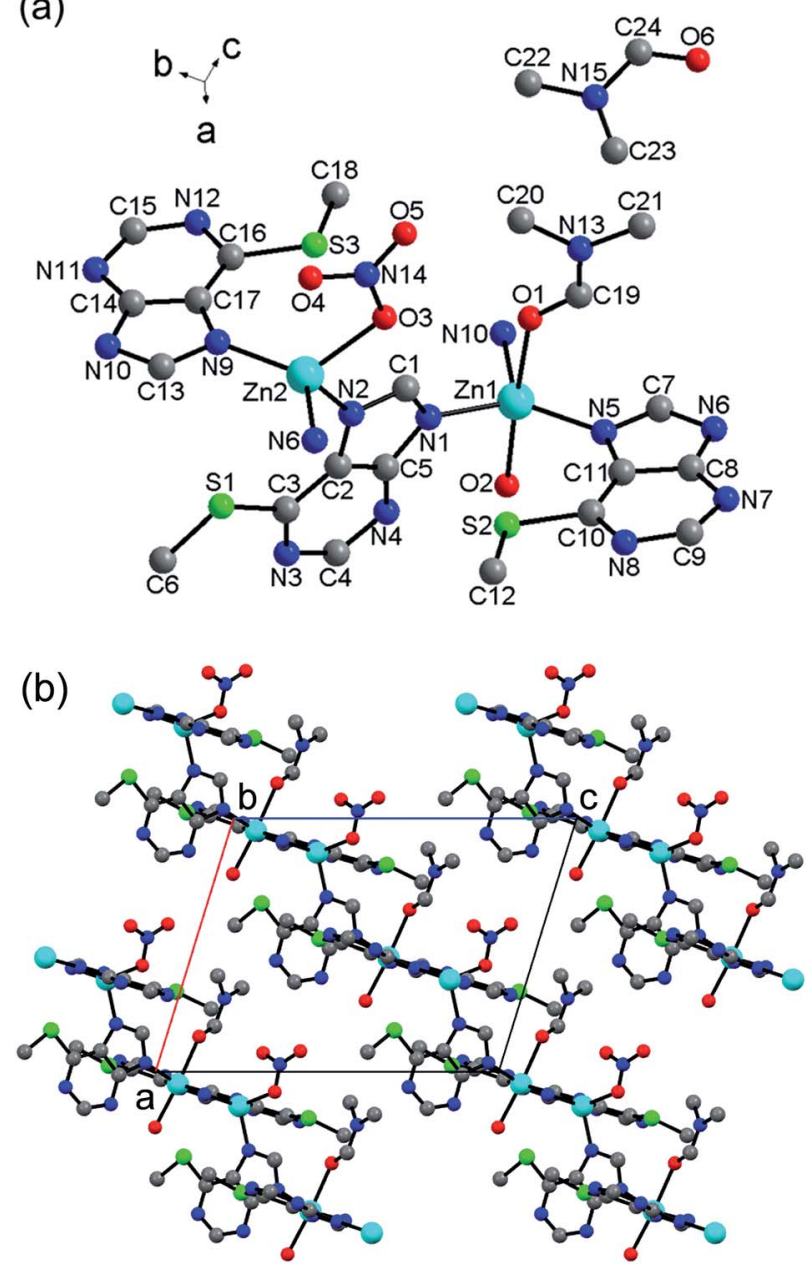

Fig. 4 Crystal structure of 1 . (a) Asymmetric unit and (b) crystal packing along the $b$ axis showing the unit cell. $\mathrm{Zn}, \mathrm{N}, \mathrm{C}, \mathrm{O}$, and $\mathrm{S}$ atoms are coloured in blue, dark blue, grey, red and green, respectively. Lattice DMF molecules in (b) and $\mathrm{H}$ atoms are omitted for clarity.
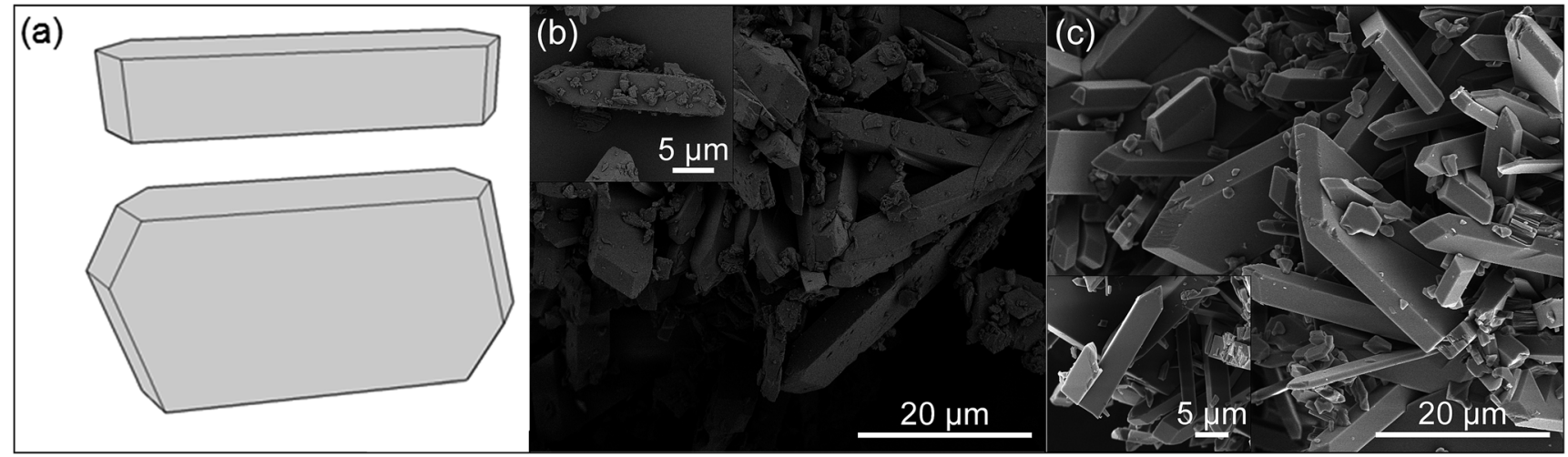

Fig. 3 (a) Schematic representation of type I (top) and type II (bottom) crystals. SEM images of 1: (b) as-synthesized and (c) purified. 
patterns is seen, confirming the existence of a unique crystalline phase without impurities in the whole sample.

CrysAlis software ${ }^{51}$ makes it possible to determine the Miller indices of crystal faces in such a way that the crystallographic orientation may be related to the crystal shape of $\mathbf{1}$. The largest face, delimited by violet lines in Fig. $\mathrm{S} 7, \dagger$ has been assigned as the plane $\left(\begin{array}{lll}0 & 1 & 0\end{array}\right)$ with CrysAlis software ${ }^{51}$ according to the law of rational indices. The plane containing the crystal face perpendicular to (llll $\left.\begin{array}{lll}0 & 0\end{array}\right)$ marked with an orange line in Fig. S7† corresponds to $\left(\begin{array}{lll}-1 & 0 & 1\end{array}\right)$. It is denoted by another orange line in the crystal structure of the same figure. The crystal shape with its layers (black dashed lines) is oriented making its plane $\left(\begin{array}{lll}-1 & 0 & 1\end{array}\right)$ coincide with that drawn in the crystal structure. It is observed that layers in the crystal structure are coplanar to sheets in the crystal shape. Thereby, layer planes of the physical crystal of 1 seem to belong to the $\left(\begin{array}{lll}-1 & 0 & 1\end{array}\right)$ family. Accordingly, the presence of marks on the $\left(\begin{array}{lll}-1 & 0 & 1\end{array}\right)$ crystal face was appreciated in several SEM images (Fig. S8†).

\section{Thermogravimetric studies of 1}

Fig. S9 $\uparrow$ shows the TGA and differential thermogravimetric (DTG) curves of 1 under air and nitrogen environments. Both TGA traces are overlapped up to $450{ }^{\circ} \mathrm{C}$, approximately. The

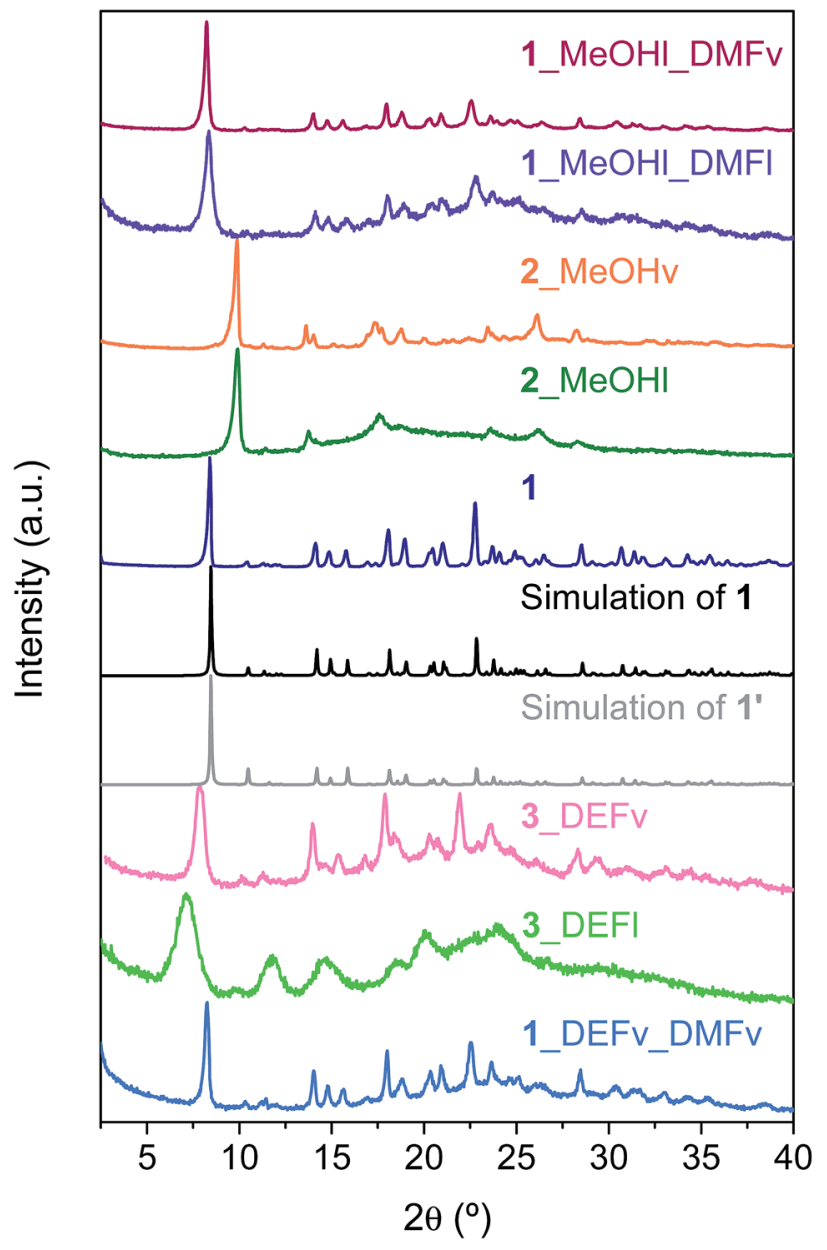

Fig. 5 PXRD patterns of products obtained in this work and simulated patterns of 1 and $1^{\prime}$ from single crystal $X$-ray data. initial weight loss of 10.4 and $10.9 \%$ at $25-140{ }^{\circ} \mathrm{C}$ for air and nitrogen conditions, respectively, was attributed to the release of lattice DMF and coordination $\mathrm{H}_{2} \mathrm{O}$ (calculated $10.7 \%$ for air). The second weight loss between 230 and $320{ }^{\circ} \mathrm{C}$ was 16.5 and $16.9 \%$ for air and nitrogen, respectively. This step was assigned to the removal of coordination DMF and the decomposition of $\mathrm{NO}_{3}{ }^{-}$. After $320{ }^{\circ} \mathrm{C}$, the decomposition of the network occurs, being as expected faster in air.

\section{Structure of $\mathbf{1}^{\prime}$}

Single crystal X-ray diffraction established that $\mathbf{1}^{\prime}$ exhibits a similar structure to that of $\mathbf{1}$ but without crystallization DMF molecules (Table 1 and Fig. S10 $\dagger$ ). The chemical formula of compound $\mathbf{1}^{\prime}$ determined by single X-ray diffraction is $\left[\mathrm{Zn}_{2}\left(\mu_{2}-\right.\right.$ $\left.\mathrm{mMP})_{3}\left(\mathrm{NO}_{3}\right)(\mathrm{DMF})\left(\mathrm{H}_{2} \mathrm{O}\right)\right]_{n}$. The distance between planes defined by the same type of $\mathrm{Zn}$ atoms is $10.440 \AA$ (Fig. $\mathrm{S} 11 \dagger$ ), which is quite similar to that found in structure 1 (10.434 $\AA$ ). These results reveal that the structure of $\mathbf{1}$ was hardly affected when DMF guest molecules were removed. This phenomenon where single crystals preserve the long-range order in the lattice after external stimuli (e.g. heat, guest removal or exchange, light, pressure, etc.) is known as single crystal to single crystal transformation. ${ }^{59,60}$ The total potential solvent accessible void volume and electron count per cell $\left(308 \AA^{3}\right.$ per unit cell and 33 electrons, respectively) have been calculated with PLATON/ SQUEEZE $^{61}$ (Fig. S12†).

\section{Exchange of molecules}

DMF replaced by $\mathbf{M e O H}$. 2_MeOHl and 2_MeOHv were produced after liquid and vapour $\mathrm{MeOH}$ exchanges, respectively. Fig. 6 shows that the band at $1655 \mathrm{~cm}^{-1}$ in the FTIR spectra, attributed to the $\mathrm{C}=\mathrm{O}$ stretching of $\mathrm{DMF}$, decreases as a result of DMF removal. It seems that the DMF was almost completely released in both cases. Moreover, the $\mathrm{O}-\mathrm{H}$ band between 3000 and $3400 \mathrm{~cm}^{-1}$ increased its intensity because of the inclusion of $\mathrm{MeOH}$ molecules in the framework. Comparing the presence of DMF in the framework with respect to the linker could be useful. Thus a parameter based on FTIR data and named area ratio is presented. It is defined by the normalized relation between the area of the $\mathrm{C}=\mathrm{O}$ band from $\mathrm{DMF}$ and the sum of the areas of the $\mathrm{C}=\mathrm{N}$ band $\left(1239 \mathrm{~cm}^{-1}\right)$ and imidazole ring band $\left(1574 \mathrm{~cm}^{-1}\right)$ from the ligand (eqn (1)).

$$
\text { Area ratio }=\left|\frac{A_{\mathrm{C}=\mathrm{O}}}{A_{\mathrm{C}=\mathrm{N}}+A_{\mathrm{Im}}}\right|_{\text {Normalized }}
$$

The bar graph in Fig. 7a contrasts the amount of exchanged DMF using the area ratio parameter. In both the liquid and the vapour exchanges, a decrease in the quantity of DMF over time is seen. The TGA curves of 2_MeOHl and 2_MeOHv (Fig. S13a $\dagger$ ) display that the first weight loss decreased to lower temperatures (below $100{ }^{\circ} \mathrm{C}$ ) relative to 1 . This was attributed to the incorporation of $\mathrm{MeOH}$ molecules. The second step was reduced to 13.7 and $14.3 \%$ for 2_MeOHl and 2_MeOHv, respectively, pointing to an elimination of ligand DMF. The PXRD patterns of both methods (Fig. 5) reveal that the new 


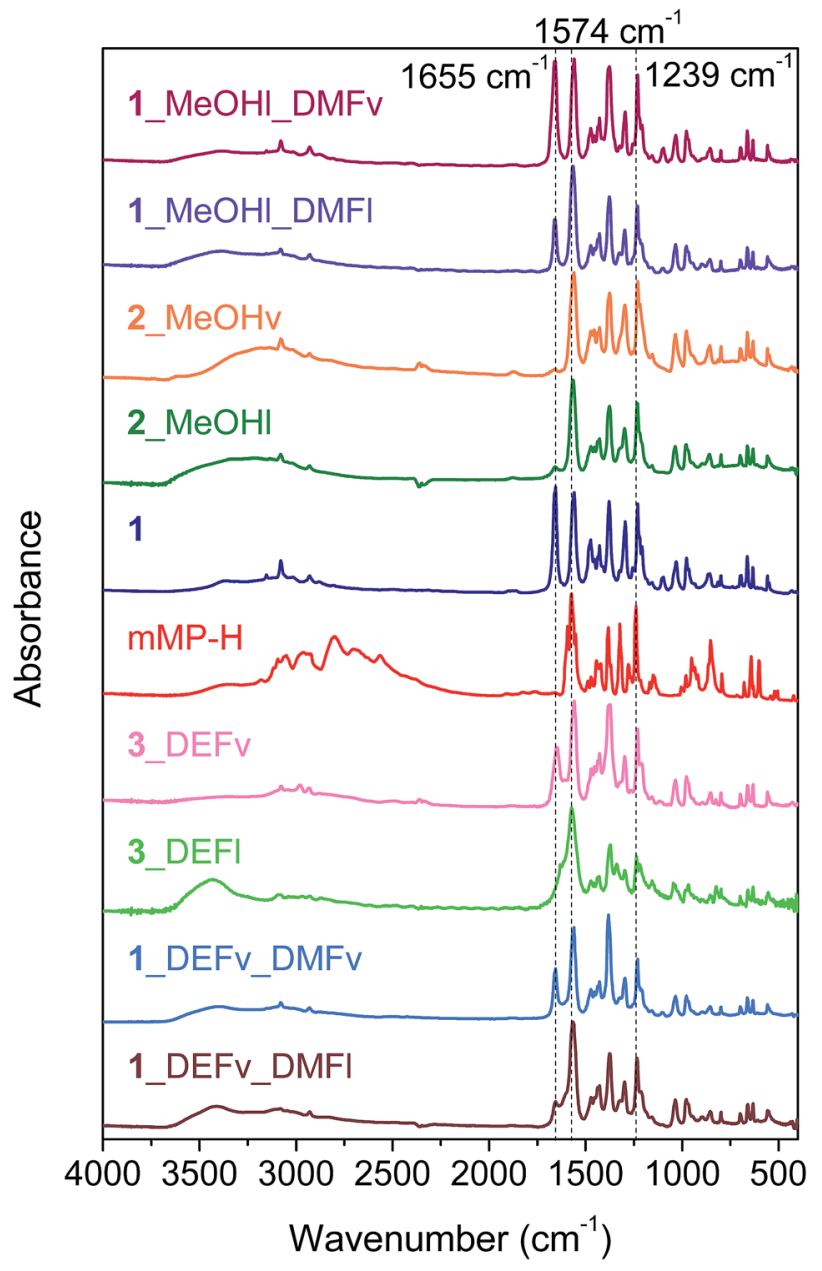

Fig. 6 FTIR spectra of some products studied in this work and that of mMP-H.

structures are observed to be similar, but different from that of 1. Nonetheless, when vapour $\mathrm{MeOH}$ is used to perform the exchange, the product obtained is more crystalline. The reflection at the lowest $2 \theta$ angle $\left(8.4^{\circ}\right)$ was shifted toward a higher value in both cases $\left(9.9^{\circ}\right)$, hence a structure contraction is likely to have occurred. This shrinkage may have been provoked by the removal of crystallization and ligand DMF. This structure contraction is not evident by SEM images (Fig. S14 and S15†). In agreement with PXRD, small and non-crystalline particles are seen on crystals of 2_MeOHl. It should be noted that marks of layers are perceptible in crystals of 2_MeOHl and mainly 2_MeOHv. Similar experiments with $\mathrm{H}_{2} \mathrm{O}$ in liquid phase instead of $\mathrm{MeOH}$ were carried out. The PXRD results show that 1 hardly retains its crystallinity after soaking with water for 3 d (Fig. S16†).

Bearing in mind all the aforementioned results and that $\mathrm{MeOH}$ and DMF have a different shape and size, framework $\mathbf{1}$ is believed to adapt to $\mathrm{MeOH}$ molecules or to suffer a shift in its coordination giving rise to a new phase (2).

DMF replaced by DEF. The introduction of $\mathrm{MeOH}$ into the framework of $\mathbf{1}$ has been studied, and a contraction in the structure was observed probably due to an approach between

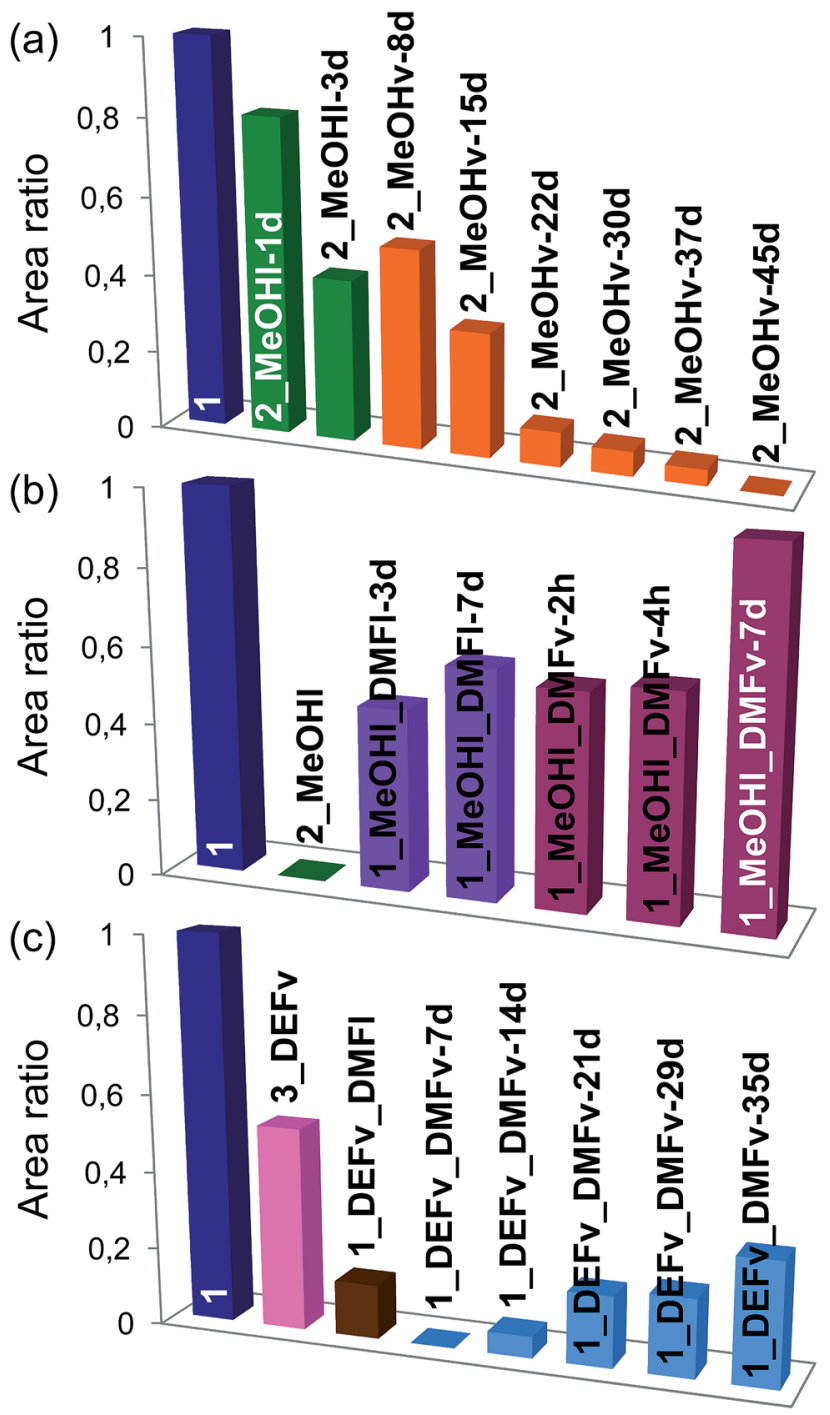

Fig. 7 Area ratios calculated with FTIR data using eqn (1). (a) Exchange of DMF by $\mathrm{MeOH}$ (l and v) over time. Framework recovery using DMF (l and v) after exchange of (b) liquid $\mathrm{MeOH}$ and (c) vapour DEF.

the layers. Taking into account this interesting result, if a molecule larger than that of DMF was utilized, an expansion would be expected. Therefore, similar processes were carried out but employing DEF instead of MeOH. 3_DEFl and 3_DEFv were obtained after the liquid and vapour phase contact, respectively. The FTIR spectra (Fig. 6) reveal that the $\mathrm{C}=\mathrm{O}$ band was shifted to smaller wavenumbers $\left(1631 \mathrm{~cm}^{-1}\right.$ for 3_DEFl and $1650 \mathrm{~cm}^{-1}$ for 3_DEFv). Fig. S17† shows an enlargement of the FTIR spectra to better perceive the mentioned band shift. The $\mathrm{C}=\mathrm{O}$ band of DEF solvent usually arises at $1643 \mathrm{~cm}^{-1}$ whereas the $\mathrm{C}=\mathrm{O}$ band of DMF appears at $1653 \mathrm{~cm}^{-1} \cdot{ }^{62}$ Accordingly, the $\mathrm{C}=\mathrm{O}$ band displacement may have been caused by the presence of DEF in the material. TGA curves (Fig. S13b $\dagger$ ) do not clarify the presence of DEF. The PXRD patterns of both 3_DEFl and 3_DEFv (Fig. 5) were distinct from those of 1 and 2 . The first reflection was moved to a lower Bragg angle (7.1 ${ }^{\circ}$ for $3 \_D E F l$ and $7.8^{\circ}$ for $\left.3 \_D E F v\right)$ pointing to a structure expansion upon exchanging DMF for 
DEF. Moreover, the PXRD curves showed larger amorphous contributions, especially that of the liquid exchanged sample. SEM images of 3_DEFv (Fig. S18 $\dagger$ ) confirm the results seen by PXRD studies. The larger size of the DEF molecule provokes a separation between the layers. Thus, the interlayer interaction decreases giving rise to an exfoliated product. As observed above in the $\mathrm{MeOH}$ case, considering the greater crystallinity of 3_DEFv, the vapour phase insertion method represents an improvement over the method carried out in liquid phase.

\section{Recovery of the framework}

MeOH replaced by DMF. 2_MeOHl was exposed to liquid and vapour DMF producing 1_MeOHl_DMFl and 1_MeOHl_DMFv, respectively. The FTIR spectra in Fig. 6 show that the $\mathrm{C}=\mathrm{O}$ band increased its intensity in both procedures. The amount of DMF recaptured by the framework over the vapour phase after $7 \mathrm{~d}$ is close to that of compound $\mathbf{1}$ (Fig. 7b). The TGA curves of both samples (Fig. S13c $\dagger$ ) resemble that of compound 1, especially 1_MeOHl_DMFv. This indicates that most of DMF molecules were reacquired, confirming the results of FTIR analysis. The PXRD patterns (Fig. 5) show that the initial form of 1 was recovered, although the product 1_MeOHl_DMFl was not as crystalline as 1_MeOHl_DMFv. Thus, the exchange of lattice and coordination DMF is completely reversible.

The framework flexibility is believed to provoke the reversible exchange by means of an adjustment of the skeleton of $\mathbf{1}$ to incorporate molecules or a change in the coordination environment around $\mathrm{Zn}$ atoms. Consequently, this new material could be used, for instance, in sensor technology.

MeOH replaced by DMF. The ability to restore the structure of 1 after replacing DMF by DEF was also studied. Both liquid and vapour phase exchanges were carried out on 3_DEFv obtaining 1_DEFv_DMFl and 1_DEFv_DMFv, respectively. The FTIR spectra of these samples (Fig. 6 and S17†) show that the intensity of the $\mathrm{C}=\mathrm{O}$ band did not augment but decreased. This trend is also detected observing the area ratios in Fig. 7c. This could indicate that all the DEF molecules have to leave the framework before DMF enters. Furthermore, the area ratio for vapour phase recovery increased over time, although the value from 1 was not attained after $35 \mathrm{~d}$. TGA characterization of 1_DEFv_DMFv (Fig. S13c $\dagger$ ) displays that several DMF molecules were recaptured, achieving a curve close to that of 1 . The PXRD pattern of 1_DEFv_DMFv (Fig. 5) shows that peaks were shifted to higher $2 \theta$ angles, almost reaching the initial values from 1. The first reflection placed at $7.8^{\circ}$ in 3_DEFv was shifted to $8.3^{\circ}$ in 1_DEFv_DMFv while it was found at $8.4^{\circ}$ in compound 1. This suggests that the starting structure was mostly recovered, probably due to the reincorporation of nearly all the DMF molecules. Unlike the DMF replacement by $\mathrm{MeOH}$, the approach of DMF molecules to $\mathrm{Zn} 1$ cores is more difficult because the presence of DEF molecules as linkers generates less available void. Since 1_DEFv_DMFl was practically amorphous, its TGA curve and PXRD pattern have been omitted. This again stresses the goodness of vapour phase exchange.

\section{Insight into the applications of 2_MeOHv}

As the space between layers is occupied by DMF molecules, adsorption of $\mathrm{CO}_{2}$ and $\mathrm{N}_{2}$ on 1 was negligible. Thus sorption studies were carried out on 2_MeOHv samples. 2_MeOHv was only capable of adsorbing $0.4 \mathrm{mmol} \mathrm{g}^{-1}$ of $\mathrm{CO}_{2}$ at $1 \mathrm{bar}$ (see Fig. S19†). Although the $\mathrm{CO}_{2}$ adsorption is not high, when compared to various PCPs (see Table 2), a great capability to adsorb $\mathrm{CO}_{2}$ molecules is observed in spite of the poor BET surface area $\left(3 \mathrm{~m}^{2} \mathrm{~g}^{-1}\right)$ (Fig. $\left.\mathrm{S} 20 \dagger\right)$. It has been reported that $\mathrm{CO}_{2}$ can interact with open metal sites through one of the oxygen lone pair orbitals producing adducts with an end-on arrangement. ${ }^{69,70}$ Therefore, it is thought that a shift in the coordination environment of $\mathrm{Zn}$ occurs during $\mathrm{MeOH}$ incorporation creating coordinatively unsaturated metal sites (CUS) accessible to grafting $\mathrm{CO}_{2}$ molecules on the cation forming $\mathrm{Zn}^{2+} \cdots \mathrm{O}=\mathrm{C}=\mathrm{O}$ end-on adducts. The $\mathrm{CO}_{2}$ uptake for compound 2_MeOHv might also have been enhanced by the Lewis basic sites from the mMP ligand (nitrogen atoms of imidazole and pyrimidine rings). ${ }^{71,72}$

A rational choice of metal and organic building blocks allows the properties and structures of CPs to be tailored. $\mathrm{mMP}-\mathrm{H}$ is a purine molecule with a thiomethyl $\left(-\mathrm{SCH}_{3}\right)$ substituent at the 6-position and four nitrogen atoms at positions 3, 6, 7 and 9 (Fig. 1). Recently, a number of research groups have demonstrated that functionalizing silica ${ }^{73,74}$ and $\mathrm{PCPs}^{75-78}$ with groups containing sulphur is effective for heavy metal removal from aqueous and non-aqueous media. In particular, Zhou et al. reported a porous coordination network with reversible adsorption of $\mathrm{HgCl}_{2}$ enabled by thiomethyl groups. ${ }^{76} \mathrm{He}$ et al. showed that functionalizing MOF-5 ligand with thioether side chains resulted in an improvement in metal uptake and photoluminescence for both sulphur-substituted linker and sulphursubstituted MOF-5. ${ }^{75}$ Other coordination compounds with nitrogenous organic linkers have shown luminescent properties with potential application in electroluminescent and sensor devices. ${ }^{5}$ Fluorescence is not only provided by organic bridging ligands, but also by metal centres. The photoluminescent characteristics of coordination compounds with mono or polynuclear $\mathrm{d}^{10}$ metal (e.g. $\mathrm{Cd}(\mathrm{II}), \mathrm{Zn}(\mathrm{II})$, or $\mathrm{Cu}(\mathrm{I})$ ) cores could represent interesting options in the field of fluorescenceemitting materials. ${ }^{4,79}$ Several examples of Zn-CPs with luminescent properties are available in bibliography. ${ }^{\mathbf{8 0 , 8 1}}$ Since framework 1 combines two $\mathrm{Zn}$ ions as metal centres and

Table $2 \mathrm{CO}_{2}$ adsorption capacities for several PCPs at 1 bar and $273 \mathrm{~K}$

\begin{tabular}{lclll}
\hline & & \multicolumn{2}{l}{ Capacity } & \\
\cline { 3 - 4 } Material & $\begin{array}{l}\text { BET surface area } \\
\left(\mathrm{m}^{2} \mathrm{~g}^{-1}\right)\end{array}$ & $\left(\mathrm{mmol} \mathrm{g}^{-1}\right)$ & $\left(\mathrm{cm}^{3} \mathrm{~g}^{-1}\right)$ & Reference \\
\hline ZIF-100 & 595 & - & 32.6 & 63 \\
Cu-EBTC & 1852 & - & 178 & 64 \\
STU-1 & 775 & - & 70.2 & 65 \\
Cd-4TP-1 & 472.2 & 2.7 & - & 66 \\
CAU-1 & 1268 & 7.2 & - & 67 \\
NTU-105 & 3543 & - & 187 & 68 \\
2_MeOHv & 3 & 0.4 & 10.2 & This work
\end{tabular}


nitrogen-containing organic molecules with a thiomethyl function as ligands, fluorescent features would be expected. Moreover, PCPs including CUS are reported to offer a mechanism for a further separation of (quadru)polar/non-polar gas pairs such as $\mathrm{CO}_{2} / \mathrm{CH}_{4}{ }^{70,82}$ All the above mentioned properties, as well as the flexibility for restoring the original structure after guest molecules are inserted, might make 1 a perfect candidate for its application in sensor technology, heavy metal removal, and gas separation for $\mathrm{CO}_{2}$ capture.

\section{Conclusions}

A new layered coordination polymer named UZAR-S12 ([ $\mathrm{Zn}_{2}\left(\mu_{2}-\right.$ $\left.\left.\mathrm{mMP})_{3}\left(\mathrm{NO}_{3}\right)(\mathrm{DMF})\left(\mathrm{H}_{2} \mathrm{O}\right)\right]_{n} \cdot \mathrm{nDMF}\right)$ was synthesized and its structure was determined using single crystal X-ray diffraction. An exchange of DMF for $\mathrm{MeOH}$ and DEF was carried out using the corresponding solvent in the liquid or vapour phase. Crystallinity was partially lost in the liquid phase exchange; however, it was almost preserved when vapour was used. It is worth mentioning that the structure of UZAR-S12 could be recovered by the use of either liquid DMF or preferably vapour DMF. The vapour $\mathrm{MeOH}$ exchanged sample (2_MeOHv) had a relatively high $\mathrm{CO}_{2}$ adsorption $\left(0.4 \mathrm{mmol} \mathrm{g}^{-1}\right.$ at 1 bar) considering its null BET surface area. This property, its chemical composition and the above mentioned flexibility of UZARS12 may render this LCP an outstanding material for applications in several fields such as sensor devices, heavy metal removal, and $\mathrm{CO}_{2}$ capture in gas separations.

\section{Acknowledgements}

Financial support from the Spanish Ministry of Economy and Competitiveness (MAT2013-40556-R) and the European Social Fund (ESF) through the Aragón Government (DGA, T05) is gratefully acknowledged. A. P.-C. acknowledges a Ph.D. Grant from the DGA. The authors would like to acknowledge the University of Zaragoza for the use of the Servicio General de Apoyo a la Investigación-SAI and the Laboratorio de Microscopías Avanzadas (LMA) at INA.

\section{Notes and references}

1 S. R. Batten, N. R. Champness, X. M. Chen, J. GarciaMartinez, S. Kitagawa, L. Ohrstrom, M. O'Keeffe, M. P. Suh and J. Reedijk, Pure Appl. Chem., 2013, 85, 1715-1724.

2 P. Amo-Ochoa and F. Zamora, Coord. Chem. Rev., 2014, 276, 34-58.

3 J. Tao, M. L. Tong, J. X. Shi, X. M. Chen and S. W. Ng, Chem. Commun., 2000, 2043-2044.

4 R. Q. Fan, H. Chen, P. Wang, Y. L. Yang, Y. B. Yin and W. Hasi, J. Coord. Chem., 2010, 63, 1514-1530.

5 X. P. Zhou, M. Li, J. Liu and D. Li, J. Am. Chem. Soc., 2012, 134, 67-70.

6 H. K. Chae, D. Y. Siberio-Perez, J. Kim, Y. Go, M. Eddaoudi, A. J. Matzger, M. O'Keeffe and O. M. Yaghi, Nature, 2004, 427, 523-527.
7 J. R. Li, J. Sculley and H. C. Zhou, Chem. Rev., 2012, 112, 869932.

8 S. Saha, S. Chandra, B. Garai and R. Banerjee, Indian J. Chem., Sect. A: Inorg., Bio-inorg., Phys., Theor. Anal. Chem., 2012, 51, 1223-1230.

9 X. Si, C. Jiao, F. Li, J. Zhang, S. Wang, S. Liu, Z. Li, L. Sun, F. Xu, Z. Gabelica and C. Schick, Energy Environ. Sci., 2011, 4, 4522-4527.

10 X. J. Wang, P. Z. Li, Y. Chen, Q. Zhang, H. Zhang, X. X. Chan, R. Ganguly, Y. Li, J. Jiang and Y. Zhao, Sci. Rep., 2013, 3, 1-5.

11 S. C. Junggeburth, L. Diehl, S. Werner, V. Duppel, W. Sigle and B. V. Lotsch, J. Am. Chem. Soc., 2013, 135, 6157-6164.

12 T. Araki, A. Kondo and K. Maeda, Chem. Commun., 2013, 49, 552-554.

13 K. Nakagawa, D. Tanaka, S. Horike, S. Shimomura, M. Higuchi and S. Kitagawa, Chem. Commun., 2010, 46, 4258-4260.

14 Y. Inubushi, S. Horike, T. Fukushima, G. Akiyama, R. Matsuda and S. Kitagawa, Chem. Commun., 2010, 46, 9229-9231.

15 T. Rodenas, I. Luz, G. Prieto, B. Seoane, H. Miro, A. Corma, F. Kapteijn, F. X. Llabres i Xamena and J. Gascon, Nat. Mater., 2015, 14, 48-55.

16 C. Li, H. Zhang, D. Jiang and Q. Yang, Chem. Commun., 2007, 547-558.

17 S. Bhattacharjee, T. J. Dines and J. A. Anderson, J. Phys. Chem. C, 2008, 112, 14124-14130.

18 T. E. Mallouk and J. A. Gavin, Acc. Chem. Res., 1998, 31, 209217.

19 B. W. Jacobs, R. J. T. Houk, M. R. Anstey, S. D. House, I. M. Robertson, A. A. Talin and M. D. Allendorf, Chem. Sci., 2011, 2, 411-416.

20 A. Sachse, R. Ameloot, B. Coq, F. Fajula, B. Coasne, D. de Vos and A. Galarneau, Chem. Commun., 2012, 48, 4749-4751.

21 G. de Combarieu, S. Hamelet, F. Millange, M. Morcrette, J. M. Tarascon, G. Ferey and R. I. Walton, Electrochem. Commun., 2009, 11, 1881-1884.

22 J. B. Goodenough and Y. Kim, Chem. Mater., 2010, 22, 587603.

23 H. Abu Ali, M. D. Darawsheh and E. Rappocciolo, Polyhedron, 2013, 61, 235-241.

24 A. Beheshti, A. Sarkarzadeh, G. Bruno, H. A. Rudbari and V. Nobakht, Polyhedron, 2014, 79, 306-314.

25 S. Roy, B. N. Sarkar, K. Bhar, S. Satapathi, P. Mitra and B. K. Ghosh, J. Mol. Struct., 2013, 1037, 160-169.

26 V. Nobakht, A. Beheshti, D. M. Proserpio, L. Carlucci and C. T. Abrahams, Inorg. Chim. Acta, 2014, 414, 217-225.

27 G. Mukherjee and K. Biradha, Chem. Commun., 2012, 48, 4293-4295.

28 X. Hu and D. Yu, RSC Adv., 2012, 2, 6570-6575.

29 S. C. Chen, M. Hu, Z. H. Zhang, F. A. Sun, L. Wang, W. Y. Zhou, M. Y. He and Q. Chen, Transition Met. Chem., 2012, 37, 619-627.

30 M. Yu, M. Hu and Z. Wu, RSC Adv., 2013, 3, 25175-25183.

31 G. Mukherjee and K. Biradha, Chem. Commun., 2014, 50, 670-672. 
32 X. Yin, H. Chen, Y. Song, Y. Wang, Q. Li and L. Zhang, J. Colloid Interface Sci., 2014, 413, 175-182.

33 N. Getachew, Y. Chebude, I. Diaz and M. Sanchez-Sanchez, J. Porous Mater., 2014, 21, 769-773.

34 D. M. Chen, X. P. Zhang, W. Shi and P. Cheng, Cryst. Growth Des., 2014, 14, 6261-6268.

35 Y. Wen, T. Sheng, Z. Xue, Z. Sun, Y. Wang, S. Hu, Y. Huang, J. Li and X. Wu, Cryst. Growth Des., 2014, 14, 6230-6238.

36 G. N. Liu, W. J. Zhu, Y. N. Chu and C. Li, Inorg. Chim. Acta, 2015, 425, 28-35.

37 H. Q. Li, P. Wang, Y. S. Ma, H. J. Cheng, X. Y. Tang, J. M. Xie and R. X. Yuan, Inorg. Chim. Acta, 2015, 429, 252-256.

38 J. P. Garcia-Teran, O. Castillo, A. Luque, U. Garcia-Couceiro, G. Beobide and P. Roman, Dalton Trans., 2006, 902-911.

39 S. Perez-Yanez, O. Castillo, J. Cepeda, J. P. Garcia-Teran, A. Luque and P. Roman, Inorg. Chim. Acta, 2011, 365, 211219.

40 A. B. Caballero, A. Rodriguez-Dieguez, J. K. Vieth, J. M. Salas and C. Janiak, Inorg. Chim. Acta, 2011, 376, 674-678.

41 S. Perez-Yanez, G. Beobide, O. Castillo, J. Cepeda, A. Luque and P. Roman, Cryst. Growth Des., 2012, 12, 3324-3334.

42 S. Perez-Yanez, G. Beobide, O. Castillo, J. Cepeda, A. Luque and P. Roman, Cryst. Growth Des., 2013, 13, 3057-3067.

43 K. Shankar, B. Das and J. B. Baruah, Eur. J. Inorg. Chem., 2013, 2013, 6147-6155.

44 J. Thomas-Gipson, R. Perez-Aguirre, G. Beobide, O. Castillo, A. Luque, S. Perez-Yanez and P. Roman, Cryst. Growth Des., 2015, 15, 975-983.

45 J. P. Garcia-Teran, O. Castillo, A. Luque, U. Garcia-Couceiro, G. Beobide and P. Roman, Cryst. Growth Des., 2007, 7, 25942600.

46 E. C. Yang, Y. N. Chan, H. Liu, Z. C. Wang and X. J. Zhao, Cryst. Growth Des., 2009, 9, 4933-4944.

47 A. Koppenhofer, U. Hartmann and H. Vahrenkamp, Chem. Ber., 1995, 128, 779-785.

48 W. Lakomska, L. Pazderski, J. Sitkowski, L. Kozerski, M. Pelczynska, A. Nasulewicz, A. Opolski and E. Szlyk, J. Mol. Struct., 2004, 707, 241-247.

49 P. Amo-Ochoa, O. Castillo, S. S. Alexandre, L. Welte, P. J. de Pablo, M. I. Rodriguez-Tapiador, J. Gomez-Herrero and F. Zamora, Inorg. Chem., 2009, 48, 7931-7936.

50 CrysAlisPro Software, Version 1.171.36.28 (release 01-02-2013 CrysAlis171.NET), Agilent Technologies UK Ltd, Oxford, UK, 2013.

51 CrysAlisPro Software, Version 1.171.37.31 (release 14-01-2014 CrysAlis171.NET), Agilent Technologies UK Ltd, Oxford, UK, 2014.

52 A. Altomare, G. Cascarano, C. Giacovazzo and A. Guagliardi, J. Appl. Crystallogr., 1994, 27, 435.

53 G. M. Sheldrick, Acta Crystallogr., Sect. C: Struct. Chem., 2015, 71, 3-8.

54 K. Brandenburg and H. Putz, Diamond, Version 3.2i, Crystal Impact GbR, Bonn, Germany, 2012.

55 C. F. Macrae, I. J. Bruno, J. A. Chisholm, P. R. Edgington, P. McCabe, E. Pidcock, L. Rodriguez-Monge, R. Taylor, J. van de Streek and P. A. Wood, J. Appl. Crystallogr., 2008, 41, 466-470.
56 H. D. Flack, Acta Crystallogr., Sect. A: Found. Crystallogr., 1983, 39, 876-881.

57 S. Parsons, H. D. Flack and T. Wagner, Acta Crystallogr., Sect. B: Struct. Sci., 2013, 69, 249-259.

58 A. W. Addison, T. N. Rao, J. Reedijk, J. Vanrijn and G. C. Verschoor, J. Chem. Soc., Dalton Trans., 1984, 13491356.

59 Z. Yin and M. Zeng, Sci. China: Chem., 2011, 54, 1371-1394.

60 A. Calderon-Casado, G. Barandika, B. Bazan, M. K. Urtiaga, O. Vallcorba, J. Rius, C. Miravittles and M. I. Arriortua, CrystEngComm, 2011, 13, 6831-6838.

61 A. L. Spek, Acta Crystallogr., Sect. C: Struct. Chem., 2015, 71, 9-18.

62 A. Schaate, M. Schulte, M. Wiebcke, A. Godt and P. Behrens, Inorg. Chim. Acta, 2009, 362, 3600-3606.

63 A. Phan, C. J. Doonan, F. J. Uribe-Romo, C. B. Knobler, M. O'Keeffe and O. M. Yaghi, Acc. Chem. Res., 2010, 43, 5867.

64 Y. Hu, S. Xiang, W. Zhang, Z. Zhang, L. Wang, J. Bai and B. Chen, Chem. Commun., 2009, 7551-7553.

65 G. L. Li, W. D. Yin, G. Z. Liu, L. F. Ma and L. Y. Wang, J. Solid State Chem., 2014, 220, 1-8.

66 G. Givaja, P. Amo-Ochoa, C. J. Gomez-Garcia and F. Zamora, Chem. Soc. Rev., 2012, 41, 115-147.

67 G. Ferey and C. Serre, Chem. Soc. Rev., 2009, 38, 1380-1399.

68 T. Kambe, R. Sakamoto, K. Hoshiko, K. Takada, M. Miyachi, J. H. Ryu, S. Sasaki, J. Kim, K. Nakazato, M. Takata and H. Nishihara, J. Am. Chem. Soc., 2013, 135, 2462-2465.

69 A. O. Yazaydin, R. Q. Snurr, T. H. Park, K. Koh, J. Liu, M. D. LeVan, A. I. Benin, P. Jakubczak, M. Lanuza, D. B. Galloway, J. J. Low and R. R. Willis, J. Am. Chem. Soc., 2009, 131, 18198-18199.

70 D. M. D'Alessandro, B. Smit and J. R. Long, Angew. Chem., Int. Ed., 2010, 49, 6058-6082.

71 J. An, S. J. Geib and N. L. Rosi, J. Am. Chem. Soc., 2010, 132, 38-39.

72 S. Chaemchuen, N. A. Kabir, K. Zhou and F. Verpoort, Chem. Soc. Rev., 2013, 42, 9304-9332.

73 A. R. Cestari and C. Airoldi, J. Braz. Chem. Soc., 1995, 6, 291296.

74 E. F. S. Vieira, J. D. Simoni and C. Airoldi, J. Mater. Chem., 1997, 7, 2249-2252.

75 J. He, K. K. Yee, Z. Xu, M. Zeller, A. D. Hunter, S. S. Y. Chui and C. M. Che, Chem. Mater., 2011, 23, 2940-2947.

76 X. P. Zhou, Z. Xu, M. Zeller and A. D. Hunter, Chem. Commun., 2009, 5439-5441.

77 F. Ke, L. G. Qiu, Y. P. Yuan, F. M. Peng, X. Jiang, A. J. Xie, Y. H. Shen and J. F. Zhu, J. Hazard. Mater., 2011, 196, 36-43.

78 M. R. Sohrabi, Microchim. Acta, 2014, 181, 435-444.

79 W. Jing, Z. G. Ren, M. Dai, Y. Chen and J. P. Lang, CrystEngComm, 2011, 13, 5111-5118.

80 G. C. Xu, L. Zhang, Y. H. Zhang, J. X. Guo, M. Q. Shi and D. Z. Jia, CrystEngComm, 2013, 15, 2873-2880.

81 P. Suvanvapee, J. Boonmak and S. Youngme, Inorg. Chim. Acta, 2015, 437, 11-15.

82 R. Sabouni, H. Kazemian and S. Rohani, Environ. Sci. Pollut. Res., 2014, 21, 5427-5449. 